Volume 7, Issue 1, 1-5 Pages

Research Article | Open Access

ISSN (Online)- 2378-7031

AMERICAN RESEARCH JOURNALS

DOI :

\title{
The Visual Arts in a New Era: Digital Art
}

\author{
Markella-Elpida Tsichla
}

Dr. Art Historian-Museologist, Aristotle University of Thessaloniki, Greece.

\begin{abstract}
The collaboration between art and technology goes way back to the 19th century, but mainly from the period of modernism onwards (dadaism, pop art and fluxus), when many artists used technological discoveries to create original and innovative images, to expandartistic horizons, to get closer to the " masses" and to multiply theirchances to promote their work. In modern times, the outburst of this phenomenon was observed in the 1990's, when high technology and computers invaded people's lives and became part of their routine. One of the things that was directly influenced was visual arts and visual culture in general, which traditionally "resisted" the invasion of technological media in the name of the individuality of the work of art, its aesthetic quality and personal inspiration.
\end{abstract}

As a result, a new kind of art was born known as "Digital Art" (or "Art of New Media" and "Art of New Technologies", terms often used in literature), with artists channeling their imagination through the computer. It was this, combined with the use of the Internet (World Wide Web), which dramatically expanded the opportunities for artistic expression, while providing the means to two-way communication, where the user participates in the development process of the project (Interaction). This form of art soon turned into a modern "art movement", that relied heavily on the dominance of technology, which was also the case for other art forms, which critics reluctantly classified as Avant Garde. This means that contemporary digital works are also reviewedbased on the semantic range they contain as works of art. This type of art has become more and more popular and many artists abroad and in Greece, become dedicated to this form of art, while many museums choose to display their work. At the same time, a lot of universities and institutions have included computer science courses in their undergraduate and graduate programs.

KEYWORDS: Digital Art, New Media, Visual Arts, Cyberculture, Multimedia, Net Art

\section{INTRODUCTION}

The rapid evolution of technology and the digital world in recent decades has greatly influenced many aspects ofpublic life and has been linked to progress and development. One of the things that was directly influenced was visual arts and visual culture in general, which traditionally "resisted" the invasion of technological media in the name of the individuality of the work of art, its aesthetic quality and personal inspiration.

In reality, however, certainscientific and technological discoveries became attractive to artists to the extent that they improved artistic creation, and facilitated its dissemination (eg engraving, photography, video, etc.), although its "merit" as a work of art, according to Walter Benjamin (Benjamin 2013, p. 17), "was the unrepeatable vision" of the artist in the processing of objects. Scientific achievements have been used by artists since the late 19th century, such as the discoveries, for example, of the unique properties of color and light, which influenced entire movements and styles (eg, Impressionism and Modernism) (fig.1), as well as the deep philosophical dimension given - in combination with the achievements of physics - to the concepts of space and time, which was expressed mainly with cubism and other artistic movements of the 20th century (fig. 2). The concord between artistic creation and scientific achievements becomes evident when we look at the later mechanical constructions of all kinds, which became autonomous parts of the artistic repertoire of artists of dadaism and itsconsecutive forms after the war and are indisputable proof of the strong influence of technology on the arts (fig.3).

\section{ART AND DIGITALITY}

One of the first art theorists to predict, as early as 1936, the new reality and what would follow, was the scientist Walter Benjamin, who expressed the view that "technological reproducibility of the artwork changes the relation of the masses to art (Benjamin 2013, p. 29), meaning that the public benefits from this unison (the use of technology in art). Thisnotion brought up issues of "fine art" and "mass culture", issues that concern scientists from all over the world still. Similar views were also expressed a little later (1938 et seq.) 
for different reasons, but with technology and art ("Art and mass culture" with reference to the "cultural industries") as the common denominator, by philosophers-colleagues of Benjamin in the "School of Frankfurt", such as Adorno, Marcuse and Horckheimer (see Adorno \& Horkheimer 1996).

The collaboration between art and technology did not cease to exist and many avant-garde artists (especially Pop Art and the Fluxus group) viewed technology as the means and the vehicle to creating original and new images, to expand their artistic horizons, to get closer to the "masses" and to find new ways to promote their work (fig.4).

But the real revolution came later, during the 1990's and onwards, when computers became part of people's daily lives. At the same time, globalization played its part in the dissemination of knowledge and cultural goods. At the same time a new term is born "Digital Art" (or "Art of New Media", "Art of New Technologies", "Computer Art" and "Electronic Art", which are also terms often used in literature), where the artists express their imagination via a computer (fig. 5).

At the same time, the use of the Internet (World Wide Web) has dramatically increased the opportunities for artistic expression. On the one hand, "Digital Art" is enriched with new terms such as "Internet Art", "Network Art" or "Cyber Art". The "Internet Art" artists, from the earliest stages of the World Wide Web, experimented with a new possibility: nonlinearity. At the end of the 1990s, a large number of artists chose this new kind of art to express themselves which led to the establishment of the "net.art" movement (fig.6).

Furthermore, the internetoffered, artists and the public the possibility of two-way communication, giving the user the ability to participate in the development process of the project (Interaction). This way, the artists create dynamic works in which the audience acts as a co-creator. Therefore, the audience, becomes more than a mere spectator, and now acquires a more active role completing the work creatively (Wilson 2002). The interface between the artist and the "spectator" is realized through points among the two systems, so the connection between them becomes first of all semantic, while the distinct boundaries between them are abolished (Vasilakos 2015, p. 362). Interactivity is very much inherent in the "art of the Internet" and involves the element of communication and collectivity, something that generally characterizes the internet where the way of communication becomes non-hierarchical.

Additionally, the cultural experience of the spectators of digital art can be further enriched by their immersion into spaces of virtual and augmented reality (fig.7, fig.8).

In fact, Digital Art is a modern "art movement", that relies heavily on the dominance of technology, something that's happened in the past with other art forms, that critics blithelyclassified as Avant Garde. This means that contemporary digital works are also questionedregarding the semantic range they contain as works of art. The "media" is the thing that sets this type of art apart and makes it accessible to the public through appropriate and specialized knowledge.

The spread of Digital Art has been a long time coming. The outburst of the phenomenon takes place during the mature stage of postmodernism, and mainly during the 1990's. Exhibitions in major museums of modern art in Europe and the United States are constantly increasing. The evolution of this form of art has been fast-moving as it follows the rapid evolution of technology and cyberspace. The relevant exhibitions start taking place in the 1990's, initially as actions that present the possibilities of the computer, to evolve later into digital art exhibitions with all the features of a visualcreative action. A notable example is the alpha 3.4 project of the "tsunamii.net" team, which was included in Documenta XI in Kassel, Germany in 2002, where visitors were asked to walk physicallyand virtually, from the exhibition space to the Documenta website (Net Art Anthology: alpha 3.4 2002).

Art and technology go hand in hand harmoniously and creatively, and over time they complement each other,so it is no coincidence that some of the fundamental aspects of modern and contemporary art are based on the use of technology. In fact, some of the media and techniques, such as the "ready-made objects" of the dadaists, along with the "collage" and "video" by 20th century artists, provided solutions to digital artists, who processed the "ready-made images" of the computer, in order to create their own visual world (fig.9).

What is remarkable is the unprecedented promotion and dissemination of digital works of art on social media, where the artist or the public can "share" with their "friends" the work they have created. The most popular social networks where one can find digital art are Facebook, MySpace, wikiArt, flickr, deviantArt, Instagram and Photobucket, which contain mainly image type files, while if you're looking for multimedia files Youtube, Dailimotion and Vimeo are your best options.

In Greece, Digital Art took a while before it became popular and those who contributed to that end were mostly artists who had lived abroad or had studied Science. Initially, the interest was focused on video production workshops and then (mainly at the dawn of the 21st century) they evolved into centers for the creation of digital art with the full use of new media and new technology. Among the most important contributions in this field are the exhibitions of the Center for Contemporary Art of Thessaloniki, the most prominent of which is the group exhibition entitled "Digital Art: Digital Art 
- Installations" (2007), but also the recent digital audiovisual installation "data flux [12 XGA version]", by the Japanese artist Ryoji Ikeda, at the House of Letters and Arts in Athens (2019).

What is interesting is that the first Greek artists were more conservative as they strongly rejected the two-dimensional art pieces and shifted more between photography and video. However, the development since then is impressive. The techniques and media were adapted to the requirements of the online image and soon the gates of museums of modern and contemporary art opened, mainly in Athens and Thessaloniki (see Moutsopoulos 2017).

An example of digital art exhibitions in Greece worth of mentioning is the Athens Digital Arts Festival, which is the representative of Greece in the international scene of Digital

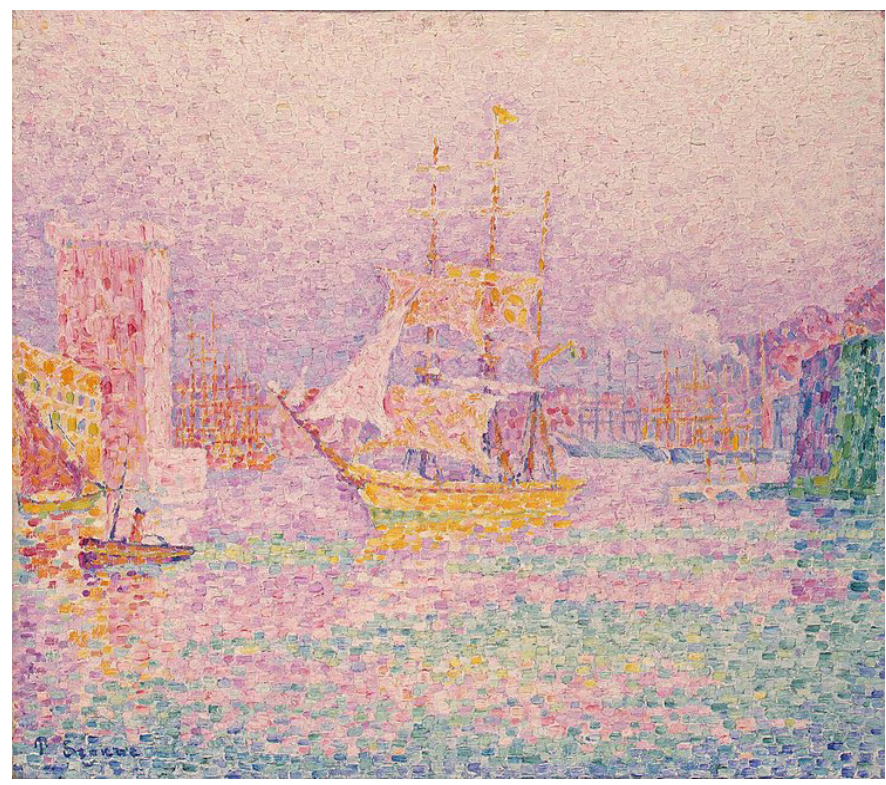

Fig.1 Signac, The port of Marseille, oil on canvas, 55x46cm., Hermitage Museum, St. Petersburg

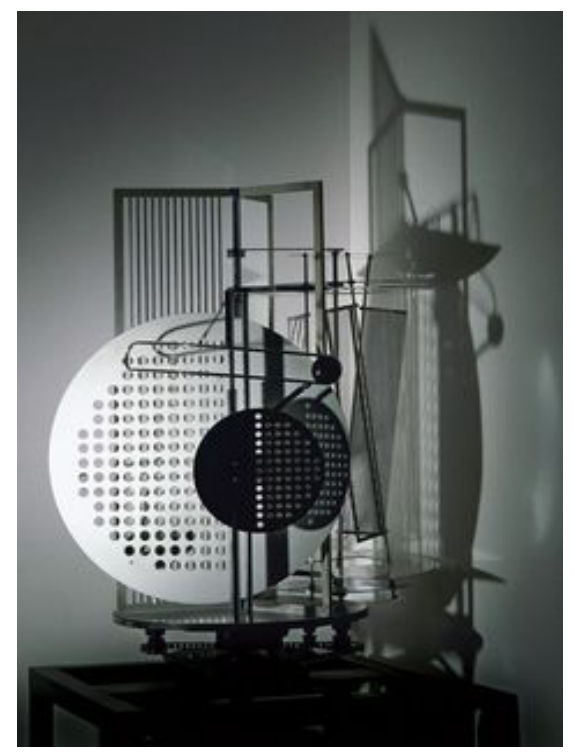

Fig. 3 L. MaholyNagy, Photo-spatial modulator, 1930, kinetic sculpture made of steel, plastic, wood, and other materials with electric motor, $151 \times 70 \times 70 \mathrm{~cm}$.
Art. With 15 years in its assets, it is an institution of digital culture, embracing art, technology, and science (Adaf.gr 2020) (fig. 10).

However, the number of Greek artists who systematically work on this genre remains too hazy to allow academic research. The same goes for collectors who may be interested in acquiring them, as well as for the critics who have dealt seriously with it. There is no data regarding the extent of digital art's reception by the public. Nevertheless, this genre (in all its forms) has been included in both undergraduate and postgraduate studies as an independent subject at many academic institutions in the country (in universities and technical institutes), while relevant studies are published, enriching the existent meager Greek bibliography on the subject.

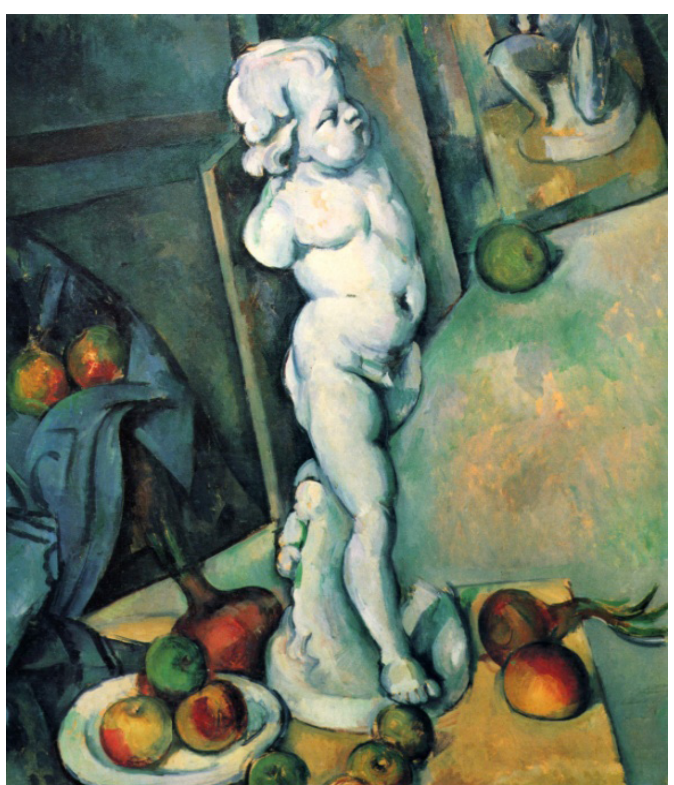

Fig.2 Cezanne, Still life with plaster and cupid, 1895, oil painting, Courtauld Gallery, London

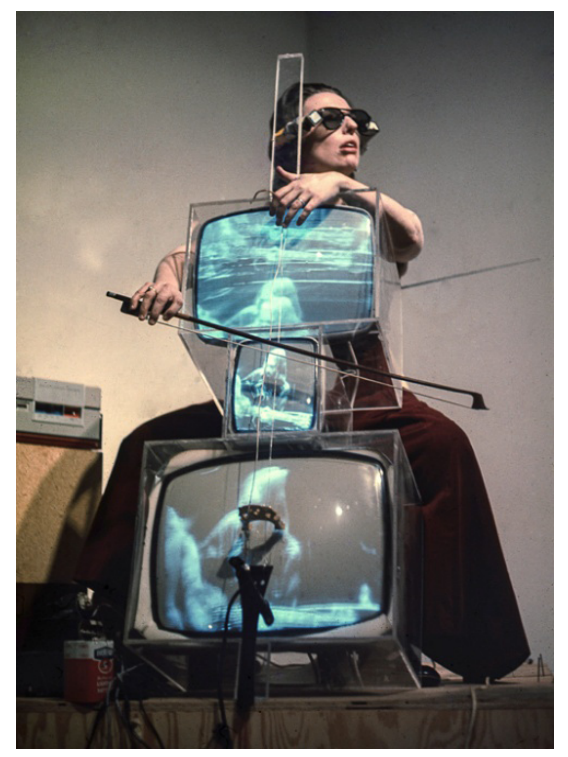

Fig.4 Charlotte Moorman performing on Nam June Paik's TV Cello wearing TV Glasses, Bonino Gallery, New York City, 1971 


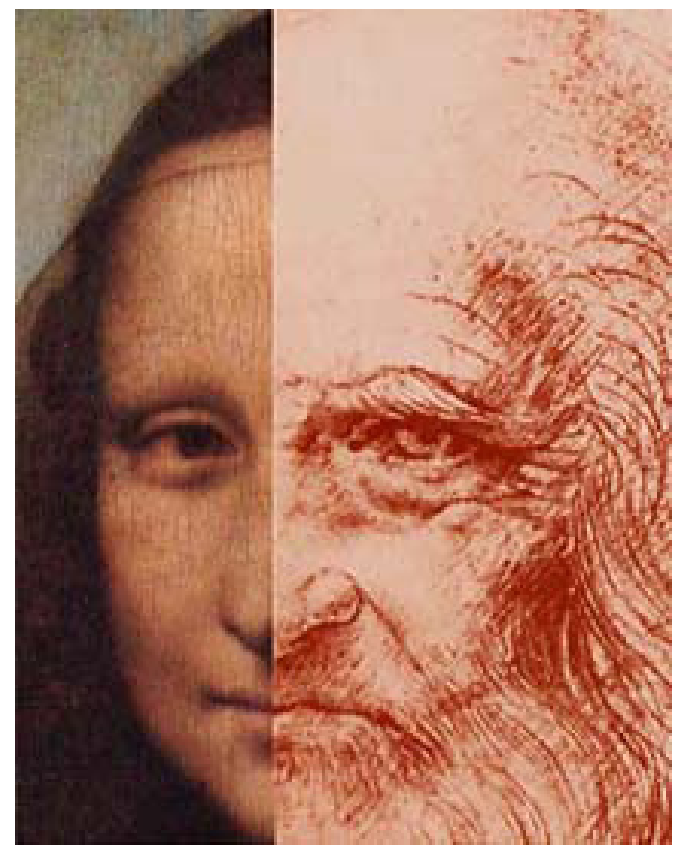

Fig.5 L. Schwartz, Mona/Leo, computer art, 1987

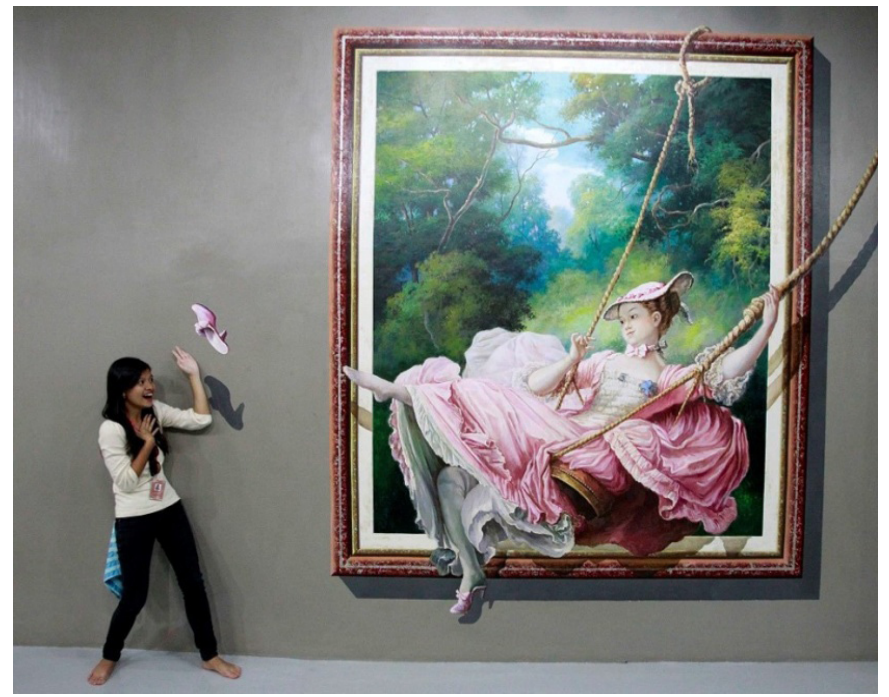

Fig. 7 Artwork in a virtual reality environment, ArtinIsland, Philippines

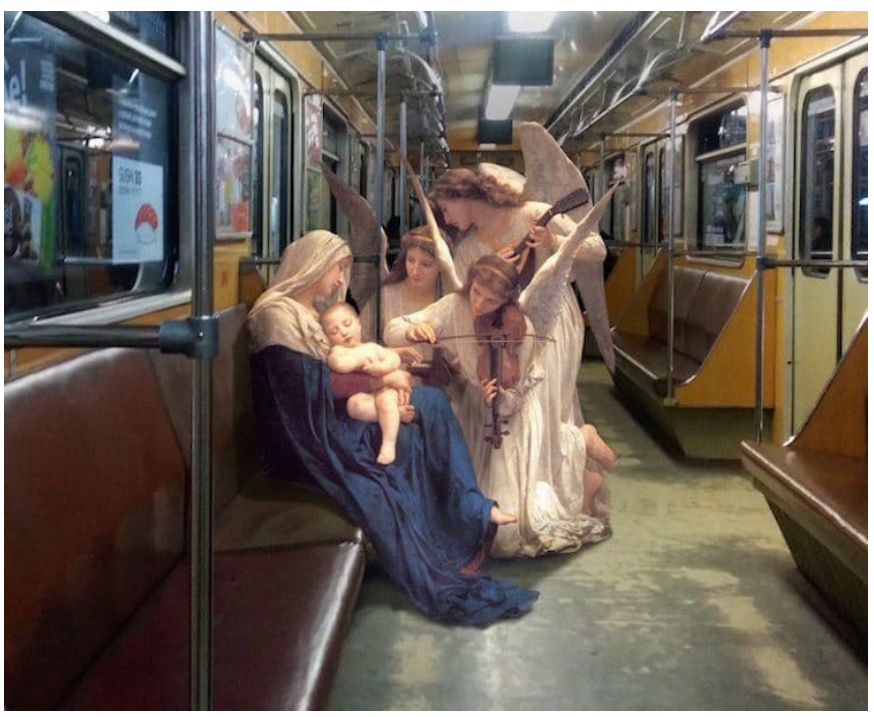

Fig. 9A. Kondakov, The Virgin Mary with the Infant in the Metro, MyModernMet

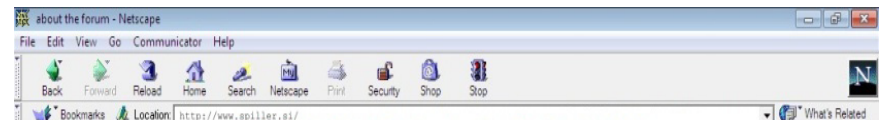

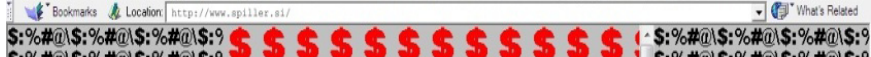

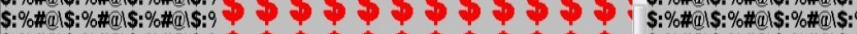

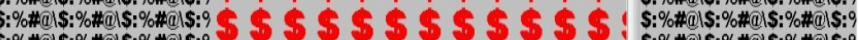

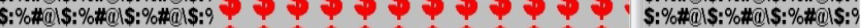

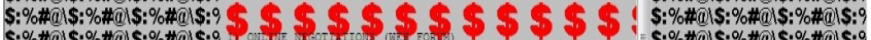

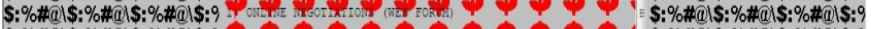

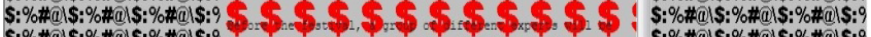

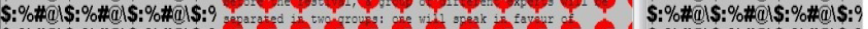

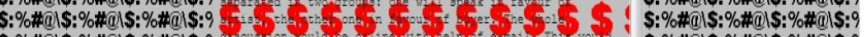

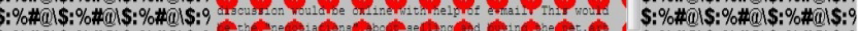

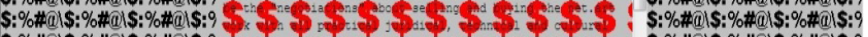

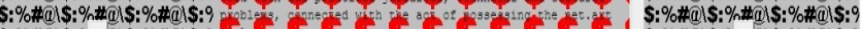

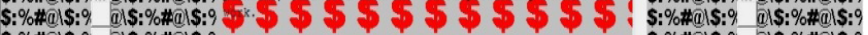

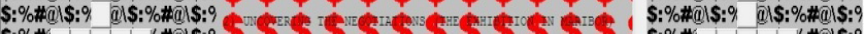

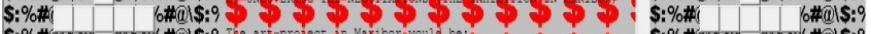

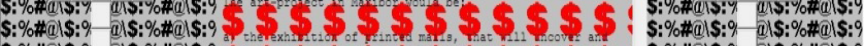

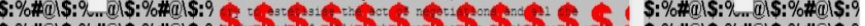

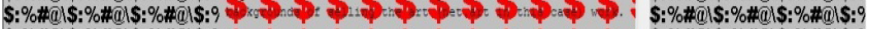

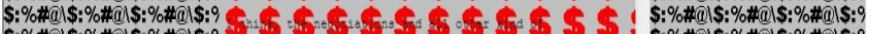

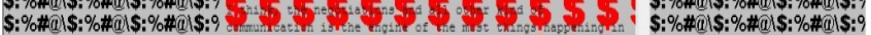

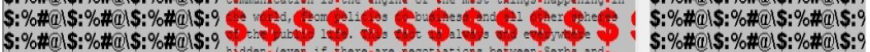

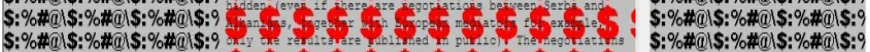

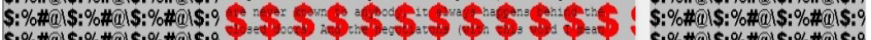

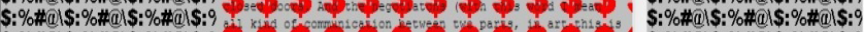

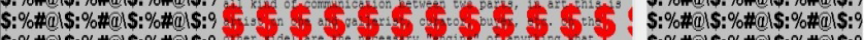

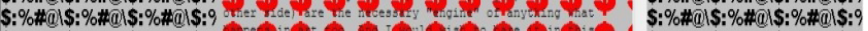

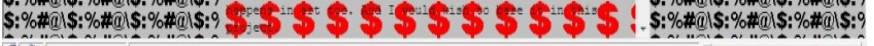

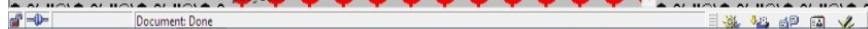
Fig.6 T. Spiller, net. art trade, 1999, net art

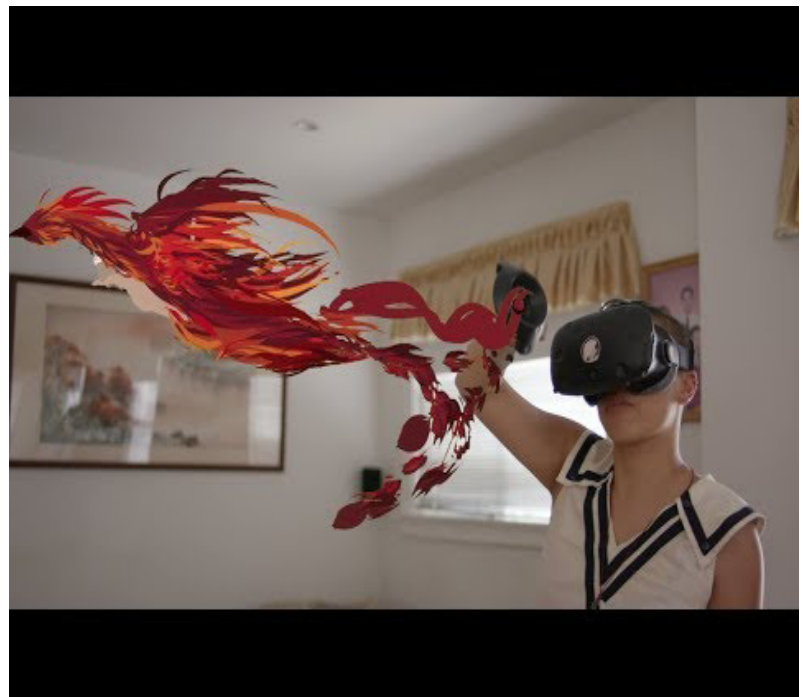

Fig.8 Artwork in an augmented reality environment, ProjectAero

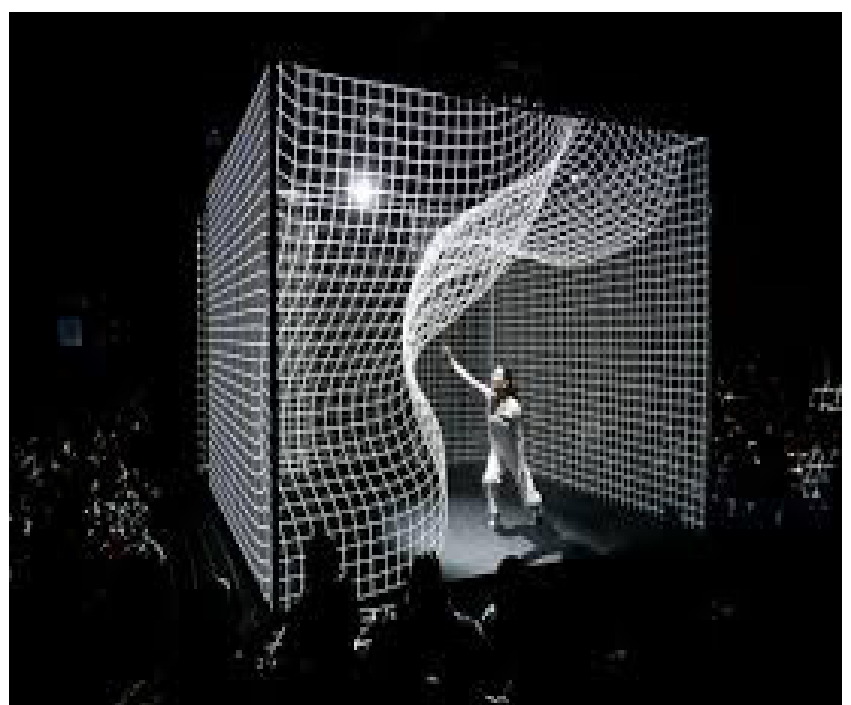

Fig. 10 Athens Digital Arts Festival 


\section{CONCLUSIONS}

It is a fact that the electronic culture, which is the subject of this paper, unites technology and culture, thematerialbased techniques with symbolic forms. These are the two sides of the same coin, where the "ideas" should be sought in the transmitters of those same ideas. For researchers, human history has followed a cyclical course, which today is characterized by electronic networks and "cyberculture" (Vryzas 2012). Therefore, cyberspace, as a dominant and powerful anthropological field, creates new market conditions, fueling development, where the visual discourse claims its own share.

Considering the social, philosophical, and cultural dimensions of this phenomenon, we can conclude that "Art", just like cyberspace, transcends social and national divisions. Apart from Art History, which has its own methods and is based on theoretical approaches, which aim to contextualize the functioning of art in a specific historical and social outline, there are other ways of connecting culture with society, with the aim of development and consolidation of knowledge. In digital art, the artist, the economist, the sociologist, the political scientist, the educator, the communicator, the advertiser, and the electronic programmer are directly connected and converge in places where the artistic ideas and the conceptual content of the works can become united to offer the desired aesthetic pleasure.

\section{REFERENCES}

1. Adorno, T. \& Horkheimer, M. (1996 [1947]). The Dialectic of the Enlightenment. Athens: Island.

2. Benjamin, W. (2013 [1936]). The work of art in the era of its technological reproducibility. Trikala: Epekeina

3. Moutsopoulos, Th. (2017). The Age of Space. Athens: Asini.

4. Wilson, S. (2002). Information Arts: Intersections of Art, Science and Technology. Cambridge, Massachusetts: The MIT Press.

5. Vasilakos, A. (2015). Forms of Digital Art. Thessaloniki: Tziolas.

6. Vryzas, K. (2012).Communication technologies and development of human society. From writing to digital networks. Thessaloniki: Vanias.

\section{Websites}

7. Adaf.gr. (2020). Athens Digital Arts Festival. [online] Available at: https://www.adaf.gr/el/ [Last Visit 5 September 2021].

8. Net Art Anthology: alpha 3.4. (2002). Net Art Anthology: alpha 3.4. [online] Available at: https://anthology. rhizome.org/alpha-3-4 [Last Visit 5 September 2021].

Citation: Markella-Elpida Tsichla, "The Visual Arts in a New Era: Digital Art”, American Research Journal of Humanities and Social Sciences, Vol 7, no. 1, 2021, pp. 1-5.

Copyright (C) 2021 Markella-Elpida Tsichla, This is an open access article distributed under the Creative Commons Attribution License, which permits unrestricted use, distribution, and reproduction in any medium, provided the original work is properly cited. 